\title{
Mental Health during COVID-19
}

\author{
Mohit Nandy ${ }^{1}$, Dr. Swaroopa Chakole ${ }^{2}$ \\ Type of Article: Review \\ Conflict of Interest: None \\ Funding: DMIMS \\ Ethical Approval: IEC, DMIMS, Wardha.
}

${ }^{1}$ Intern, Dept. of Community Medicine, Jawaharlal Nehru Medical College, Datta Meghe Institute of Medical Sciences (Deemed to be University), Sawangi (Meghe), Wardha-442001, Maharashtra, India,

${ }^{2}$ Professor, Dept. of Community Medicine, Jawaharlal Nehru Medical College, Datta Meghe Institute of Medical Sciences (Deemed to be University), Sawangi (Meghe), Wardha-442001, Maharashtra, India,

Emails: ${ }^{1}$ mohitnandy2014@gmail.com, ${ }^{2}$ drswaroopachakole@gmail.com,

\begin{abstract}
BACKGROUND

COVID-19 or coronavirus disease 2019 is the pandemic that had hit all the aspect of the human life in a negative way. Proper solutions needs to be find out before situation worsens.

SUMMARY

COVID-19 affected the mental wellbeing of all the people inhabiting the earth in some way or the other. As extreme uncertainty is attached to the event, it is impossible to forecast the future which everyone care about. In that quest we become anxious and forget to fully live the present which can be a slippingpoint to depression. Proper use of technology like telemedicine can be done to ensure larger penetration of psychological services.
\end{abstract}

CONCLUSION

More study between the effects of pandemic and its effect on mental health needs to be done. Telemedicine and communication can be the game changer in such times of distress to tackle the problem of social distress.

\section{INTRODUCTION}

The unprecedented nature of the medical emergency has been currently ongoing for almost last one year. The novel coronavirus or SARS-COV-2 is the culprit virus behind the unprecedented situation. Coronavirus disease 2019 or COVID-19 caused by SARS-COV-2 or novel coronavirus has wreaked all of the aspects of human life. Since its initial occurrence in Wuhan city of the Hubeiprovince in China,(1)its devastating consequences has been felt all over the world. From China to Europe and now in UnitedStates of America, no signs of stoppage can be seen. As of January 6, 2021, 86,809,552 number of infection caused due to COVID-19 infectious disease has been reported and $1,876,156$ case fatalities or mortalities has been registered from more than 200 regions of the world(2). The case fatality rate is way less than its previous counterparts of severe acute respiratory syndrome (SARS)(3) and Middle Eastern respiratory syndrome (MERS) and stands at one to two percent(4). But the extent of the disease and deadliness has far exceeded the previous two outbreaks making one of the worst event in the human history of last hundred century. In fact on march 11, 2020, World health Organization (WHO) was compelled to designate the COVID-19 as pandemic(5), one of its kind announcement about the disease outbreak made by WHO since its inception. Before that it was designated as public health emergency of international concern (PHEIC). United States of America, India, Brazil, Russian federation, France, and United Kingdom are the torchbearers of the most number of cases(6). In fact these six countries alone accounts for more than half of the total infection caused by the novel coronavirus and case fatalities from the same due to medical complications attached to it. Also the new mutated strain has been discovered after genomic study of the samples from United Kingdom(7) and South Africa(8). The new strain is 
supposedly seventypercent more virulent than the current one. Many countries are reporting to impose lockdown again to restrict the spread of the new virus. Many aspects of human life has been adversely affected by the COVID-19 pandemic. One of which is less talked about that is mental health. Pandemic has affected humans not only physically but also mentally. Lockdown induced loneliness, frustration, anxiety were all result of uncertainty attached to the situation(9). Many groups of population were affected differentially. Health care professionals who were and are at the forefront of the fight against COVID-19 pandemic are tremendously stressed due to working culture and anxiety attached to COVID-19 era. Elderly and pregnant women who are already designated as vulnerable section has been under great depression.Likewise students are also experiencing mild to severeanxiety and depression based on various factors. In this article the holistic overview has been done in order to understand all these topics.

\section{PSYCHOLOGICAL DISTRESS AMONG HEALTH CARE PROFESSIONALS}

A less noticed condition is brewing among the medical professionals and it is quite often neglected. The psychological distress among health care professionals is a grave cause of concern as they are the backbone of the fight against COVID-19. They are not only getting physically reduced but mentally they are on lowering side. In the initial days of the pandemic, as the uncertainty attached to the disease was tremendous, doctors and other allied health care professionals faced huge hardships in terms of social stigmatizations. Doctors and other alliedhealth care workers were attacked upon on several instances if the kin of the patient was not aware of the deadly nature of the pandemic. They were evicted from the buildings they reside, new places were barred because of possible spreading of the disease. The height of insensitivity reached when a doctor died due to COVID-19, the medically illiterate people denied him funeral space which is the fundamental right of any human being and also morally incorrect. This and many more news about such incidents createda negative sentiments among the serving health care professionals and induced a certain degree of psychological distress. Health careworkers felt that their efforts of containing the virus means nothing to people(10). The huge virulent nature of the virus had already overwhelmed the health care facilities. But the number of health care professionals per unit population is already not up to the mark. It creates unbalance as huge number of patient influx creates problems in dealing with the pandemic. Doctors and nurses were stressed that they have to work round the clock. Also they have to followguidelines which mandates compulsory donning of personal and protective equipment's (PPE) kit in order to safeguard themselves from the virus. This has created huge challenge as PPE kit cannot be intermittently worn and done away with and one has to work continuously for around 12 hours. The physical strain was so much that many worker felt low on energy and completely exhausted. Also the constant fear of transmitting the virus to their family members and loved ones was nagging them and this induces anxiety and depression(11). Contracting the virus to themselves was always present there. Sometimes lack of PPE kits and proper working gears also proved to be taking toll on mental health as one has to live in constant fear of getting infected by the lethal virus. Fatigue was a routine phenomenon as the long working hours without getting any leave has to be completed. A study conducted in Himalayan country of Nepal showed that around 41.9 percent of health care professionals had symptoms of anxiousness, three out of everyeighth health care professionals were having depression which constitutes to around 
37.5 percent and around a third of them had insomnia or sleeping sickness. Inadequate supply of preventive kits and improper implementation of mitigating measure accounted for anxiety at workplace. The huge fatalitiesamonghealth care professionals were also seen as negative news and induced anxiety. According to International nurses council more nurses had dies during the COVID19 duty and due to same complications than in First World War(12).

\section{PSYCHOLOGICAL DISTRESS AMONG POPULATION}

With the inception of the COVID-19 pandemic in early 2020, uncertainty was already coupled with it as the novelty of the disease was huge and there was no precedent of the disease spread. Steps in dark were taken and blanket measures found the most favorite option among governmental agencies as little was known about the containment of the virus. The initial steps of lockdown and movement restrictions were the result of the same along with various other nonpharmacological interventions. This left the large chunk of the population confined at home. Most of them were on their technologically advanced devices such as smartphones and television. The information explosion that people are getting form these devices are most of the time unverified and negative. This has already induced huge anxiety among the people. Home confinement means away from your loved ones and family members who might be in different city altogether, but due to lockdown and movement restrictions, it was not possible to meet them creatingfear of not seeing them physically. Main reasons of pandemic induced anxiety were fear of getting contracted with the virus, frustration, unknown anxiety, loneliness and boredom. Uncontrolled fear related to infection was widely seen(13). As the true pictures coming out of Italy and Spain of vast number of case fatalities due to COVID-
19, people were natural nervous about the grim scenario. They started any symptoms which is not even related to COVID-19 considering as COVID-19 symptoms. This had taken huge on their physical as well as mental state. Also news of some relatives being positive for the infection increases their fear and they started to worry more about theirs and families health. Man is a social animal and pandemic has separated and made them socially isolated due to high transmissibility of the viral infection. Also COVID-19 infected patient were isolated and quarantined in home or in a COVID-19 care facility. They were not allowed to meet their family members and loved ones. So do family members and loved ones were prohibited to meet the patient. The long period in isolation and no contact with the family instils a fear of missing out on various events. Especially the vulnerable sections such as elderlies and pregnant women were the hardest hit group among population. In elderlies, they are already in their solitude time and remains cut off from the mainstream events already due to their health concern. Pandemic designated them as most hit section of the society in terms of case fatalities and various guidelines regarding prohibition on the movement of the elderlies were issued in order to protect them. This creates anxiety in them which would worsens the situation. Also in pregnant women who is already in tension about the outcome of the pregnancy, pandemic adds to the woes of the mothers bearing child. They are protective about their upcoming offspring in turn under constant anxiety and fear. Frustration and boredom due to monotonous tasks and work from home has been introduces. Ban ongoing out hits the food refreshing option and render it ineffective(14).

In a study conducted among 398 respondents, stress level after trauma that is post traumatic disorder were almost four times higher in quarantined respondents than the non-quarantined one. The alexithymia traits can be one possible 
reason behind the quarantine related stress. It is known to reduce psychological resilience which can be helpful in such situation to manage the situation. It may induce suicidal behavior. Uncertainty about necessary supplies also a reason for the frustration and anxiety. Hoax spread in Infodemic like artificial shortage of commodities are creating general perception that things won't last long and they should stock up all the things necessary for survival. The needs must be addressed or assurance must be provided by government in order to ease up the tense situation. It is seen that people mostly male addicted to bad habits such as liquor consumption and other psychotropic substances have found to be indulging in domestic violence with their spouses. Loss of job and livelihood has been the reason behind building up the hidden rage and anxiety and it vented out on physically weaker spouses which is completely unacceptable. Rise in domestic violence is a grave cause of concern as generally victim is the women of the house or children's which are physicallyweaker. This can induce childhood trauma which last lifelong along with children. Women may go into depression and even become suicidal due to negative and hostile environment towards her. This needs to be stopped and proper precaution must be taken. Also several million unwanted pregnancies are expected as the lockdown as prohibited to access the necessary contraception which must be used during copulation(15).

\section{PSYCHOLOGICAL IMPACT ON STUDENTS}

According to study conducted among Chinese students there were remarkable rise in anxiety. A seven itemquestionnaire was distributed among 7143 respondents. Approximately 1 percent of the respondents showed severe symptom of anxiety, 21.3 percent students were experiencing milder symptoms of the anxiety. There were some protective factors found in the study. For example financial backup, living with parents etc. Provided cushion for the psychological distress. Urban students were more anxious as thirdlifestyle was stopped after the announcement of the lockdown. Rural students were comparatively less panicked as viral spread was less in rural areas as compared to urban areas(16). Weather was pleasant and air cleaner made at least their mood lighter. Academic delays and uncertainty attached to it made the environment hostile for the students. No information on exams and promotion to next class was given which darkens the mood of the students. Link from the study was broken and folks felt depressed. EspeciallyUncertainty has made all the schedules and future planning of students go in vain. Uncertainty about the future, distance apart from the parents, lack of financial resources and employment are the key factors affecting the youth.

\section{INFODEMIC}

Along the sidelines of the COVID-19 pandemic, there is another pandemic is brewing also known as misinformation pandemic or Infodemic. World Health Organization (WHO) has to come up with the term so as to underline and highlight the menace that it has been spreading all across the globe. Infodemic is basically transmission of unauthorized, fake messages, mis information, wrong claims, and cyber frauds and so on to exploit the ordinary person who has lesser knowledge about technology to exploit him or her emotionally, financially and to misguide him or her on various issues(17). As the penetration of technology reached several times than previous era, more and more people got hands on smartphones and internet. But they often lack digital literacy which makes them vulnerable and soft targets of such Infodemic. The problem is so deep rooted and encrypted that it is not easy to track the messages that are fake or wrong in nature. Mis information can create menace that needs separate 
machinery to handle. Some examples are eye opener and tells us why we need to tackle them at their speed. After pandemic arrived and lockdown was announces across theworld, billions of people utilized the time on being on social media and other such websites. Various messages were circulating all across social media platforms claiming fake cure about COVID-19 and urging people to try at least once. This can create huge medical disaster as self-medication in lethal disease like COVID-19 may back fire and can create another health emergency. Quackery was also on rise and various tantric and false spiritual people was claiming to have found the cure of the COVID-19 and will only give to those who are able to pay hefty amount of money. People with various contraindications need to be extra cautious before trying any medication on their own. Various testimonials of the fake patients recovered from COVID-19 about due course of treatment were doing rounds on social media(18). These were fake and need not to be believed. In the start of the lockdown hoax messages about the never ending lockdown and urging people to stock up as much as they can created a huge panic buying chain and put severe strain on logistics and distribution cycle. Also black marketing and selling fake goods were on rise and it was later understood that that message was fake but after the damage was done. These messages spread like wildfire and are difficult to trace. This also creates mental stress and widespread social distress as constant hammering of unverified negative news disheartens the people(19). Increased screen time may harm not in physical way but in mental way too. Financialfraudsters found space when lockdown was announces $(20,21)$. Various phone calls, messages and links were sent to victim in order to fraud him or her of money. Especially pensioners and age old people. They have less knowledge about how to use technology safely. This same thing was exploited and large sums of money were looted from them. Already under distress, looted and defrauded people were left helpless and were pushed in depression (22-24). Many of them have committed suicide due to these frauds.Urgent action to curb these frauds and online misappropriation of funds needs to check in order to safeguard people from another Infodemic $(25,26)$.

\section{MITIGATING STEPS}

The pandemic has brought the world at standstill and we need to find the way out. Those factors which areresilient be it humans or conditions or habits were sailed through the storm. Therefore building resilience in every aspects of our life can make us stronger inside out. ESPECIALLY mental resilience is the key as if mental health is not well then the physical health affects automatically in a negative way. Thereforemaintaining mental well being can bring overall wellness in our body. ENABLING effective communication and maintaining it can be a game changer as lack of communication can cause catastrophic change. It frees up the person with rage and anxiety that is deep hidden. Also effective communication can stimulate will power which is strongly associated in building resilience in tough times. In addition providing sufficient and minimum psychological and mental health services to all despite of their nature may prove as a screening test in the time of such social distress. Accessing or seeking psychological help is still not openly accepted in our society and considered as sign of mental illness. But that is not the case. Effective communication and solution problems of the psychologically distress patient can be effectively delivered by psychological specialist or service provider. Therefore it is essential to first accept the condition and then act upon it in order to solve it. Mental health education is a must in order to sensitize the society about these problems. OTHERWISE these 
problems culminates in top bigger which can prove fatal in the form of suicides or aggressive tendencies. Usage of telemedicine can be effectively fine to serve the purpose of consultations. Wide range and constant connection can be ensured to multiple patient can be achieved through telemedicine. Also no rule of movement restrictions will be violated as access to the technology only needs smart phones and internet connection which are by far now everywhere available.

\section{CONCLUSION}

Pandemic has done one thing good and that is raising voice about mental illnesses. The socially distressed situation has create a major challenge and needs huge investment in various models dealing with the same. Infodemic needs equally raging response from the competent authority along with the help of non-governmental organization and civil society groups in order to deal with the problem. The anxiety and depression becomes graver and graver if left untreated or unexamined at first place. Various recreational activities can be done in order to release pressure form patients mind. Yoga and meditation are the places where one can take refuge and experience blissfulness. Remaining positive in all the situation may also be helpful in tackling such situation. After all mental wellbeing ensures physical wellbeing.

\section{REFERENCES}

1. Dushyant Bawiskar, Pratik Phansopkar, Ayurva Vilas Gotmare. COVID-19 Facets: Pandemics, Curse and Humanity. Int J Res Pharm Sci. 2020 Aug 6;11(SPL1):385-90.

2. COVID-19 Map [Internet]. Johns Hopkins Coronavirus Resource Center. [cited 2021 Jan 7]. Available from:

https://coronavirus.jhu.edu/map.html

3. Batawi S, Tarazan N, Al-Raddadi R, Al Qasim E, Sindi A, AL Johni S, et al. Quality of life reported by survivors after hospitalization for Middle East respiratory syndrome (MERS). Health Qual Life Outcomes [Internet]. 2019 Jun 11 [cited 2020 Dec 18];17(1):101. Available from: https://doi.org/10.1186/s12955-0191165-2

4. Ngai JC, Ko FW, Ng SS, To K-W, Tong M, Hui DS. The long-term impact of severe acute respiratory syndrome on pulmonary function, exercise capacity and health status.Respirol Carlton Vic. 2010 Apr;15(3):543-50.

5. WHO Director-General's opening remarks at the media briefing on COVID-19 - 11 March 2020.pdf.

6. WHO Coronavirus Disease (COVID19) Dashboard [Internet]. [cited 2021 Jan 7]. Available from: https://covid19.who.int

7. Wise J. Covid-19: New coronavirus variant is identified in UK. BMJ [Internet]. 2020 Dec 16 [cited 2020 Dec 23];371:m4857. Available from: https://www.bmj.com/content/371/b mj.m4857

8. CDC. Coronavirus Disease 2019 (COVID-19) [Internet]. Centers for Disease Control and Prevention. 2020 [cited 2020 Nov 25]. Available from: https://www.cdc.gov/coronavirus/201 9-ncov/hcp/clinical-guidancemanagement-patients.html

9. The Lancet null. India under COVID-19 lockdown. Lancet Lond Engl. 2020 25;395(10233):1315.

10. Gualano MR, Lo Moro G, Voglino G, Bert F, Siliquini R. Effects of Covid-19 Lockdown on Mental Health and Sleep Disturbances in Italy. Int J Environ Res Public Health [Internet]. 2020 Jan [cited 2020 Oct 16];17(13):4779. Available from: https://www.mdpi.com/16604601/17/13/4779

11. Psychological_Impact_of_COVID19_in_pregnant_women.pdf.

12. ICN confirms 1,500 nurses have died from COVID-19 in 44 countries and 
estimates that healthcare worker COVID-19 fatalities worldwide could be more than 20,000 [Internet]. ICN International Council of Nurses. [cited 2020 Dec 17]. Available from: https://www.icn.ch/news/icn-

confirms-1500-nurses-have-died-

covid-19-44-countries-and-estimateshealthcare-worker-covid

13. Tee ML, Tee CA, Anlacan JP, Aligam KJG, Reyes PWC, Kuruchittham V, et al. Psychological impact of COVID-19 pandemic in the Philippines. J Affect Disord. 2020 Dec 1;277:379-91.

14. Luo M, Guo L, Yu M, Jiang W, Wang $H$. The psychological and mental impact of coronavirus disease 2019 (COVID-19) on medical staff and general public - A systematic review and meta-analysis. Psychiatry Res. 2020 Sep;291:113190.

15. Serafini G, Parmigiani B, Amerio A, Aguglia A, Sher L, Amore M. The psychological impact of COVID-19 on the mental health in the general population.QJM Mon J Assoc Physicians. 2020 Jun 22;

16. Cao W, Fang Z, Hou G, Han M, Xu $\mathrm{X}$, Dong $\mathrm{J}$, et al. The psychological impact of the COVID-19 epidemic on college students in China. Psychiatry Res. 2020 May;287:112934.

17. Solomon DH, Bucala R, Kaplan MJ, Nigrovic PA. The "Infodemic" of COVID-19. Arthritis Rheumatol Hoboken NJ. 2020 Aug 2;

18. Blendon RJ, Koonin LM, Benson JM, Cetron MS, Pollard WE, Mitchell EW, et al. Public response to community mitigation measures for pandemic influenza. Emerg Infect Dis. 2008 May;14(5):778-86.

19. COVID-19 Facets: Pandemics, Curse and Humanity | International Journal of Research in Pharmaceutical Sciences [Internet]. [cited 2020 Oct 17]. Available from: https://pharmascope.org/ijrps/article/ view/2731
20. Chaudhari, B.V., and P.P. Chawle. "Life Lessons of the Pandemic "COVID-19"." International Journal of Research in Pharmaceutical Sciences 11, no. Special Issue 1 (2020): 469-71. https://doi.org/10.26452/ijrps.v11iSPL 1.2814 .

21. Chhapare, S., and R.S. Bhutada. "COVID-19: A Pandemic Situation Review Article." International Journal of Research in Pharmaceutical Sciences 11, no. Special Issue 1 (2020): 1110-15. https://doi.org/10.26452/ijrps.v11iSPL 1.3545 .

22. Gaidhane, S., N. Khatib, Q.S. Zahiruddin, A. Gaidhane, S. Telrandhe, and P. Godhiwal. "Depression, Anxiety and Stress among the General Population in the Time of COVID-19 Lockdown: A Cross-Sectional Study Protocol." International Journal of Research in Pharmaceutical Sciences 11, no. Special Issue 1 (2020): 360-64. https://doi.org/10.26452/ijrps.v11iSPL 1.2726 .

23. Ghate, V.C., S. Borage, and P. Shelotkar. "Covid-19 in Pregnant Women." International Journal of Research in Pharmaceutical Sciences 11, no. Special Issue 1 (2020): 430-32. https://doi.org/10.26452/ijrps.v11iSPL 1.2805 .

24. Ghogare, A., D. Chowdhury, P. Patil, and G. Vankar. "Schizophrenia with Obsessive-Compulsive Symptoms Neuropsychiatric Manifestation in the Context of Underlying Brain Pathology: A Case Report from Rural Tertiary Health-Care Center from Maharashtra." Journal of Datta Meghe Institute of Medical Sciences University 15, no. 2 (2020): 295-99. https://doi.org/10.4103/jdmimsu.jdmim su_34_20.

25. Philip, M., C.C. Mahakalka, M.N. Kapl, S. Kshirsagar, and A. Shukla. "Mental and Behavioral Changes during COVID 19 Pandemic and How 
to Deal with It." Journal of Critical Reviews 7, no. 8 (2020): 1105-12. https://doi.org/10.31838/jcr.07.08.233.

26. Balwani, T.R., S.G. Dubey, S. Sathe, A. Chandak, and S. Khubchandani. "Assessment of Fear Psychosis and Practice Modification in Dental Fraternity to Fight against COVID-19a Survey in Central India Population." International Journal of Research in Pharmaceutical Sciences 11, no. Special Issue 1 (2020): 1339-45. https://doi.org/10.26452/ijrps.v11iSPL 1.3634 . 